\title{
INTERNACIONALIZAÇÃO/TRADUÇÃO DE UM SITE UNIVERSITÁRIO
}

\section{INTERNACIONALIZATION/TRANSLATION OF A UNIVERSITY WEBSITE}

\author{
Leonardo Penha MESQUITA \\ Pesquisador autônomo \\ Ribeirão Preto, São Paulo, Brasil \\ orcid.org/0000-0003-0870-5569 \\ lpmesquita@gmail.com
}

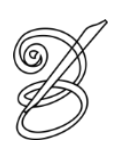

\author{
Igor Antônio Lourenço DA SILVA \\ Universidade Federal de Uberlândia \\ Instituto de Letras e Linguística \\ Bacharelado em Tradução \\ Uberlândia, Minas Gerais, Brasil \\ orcid.org/0000-0003-0738-3262 \\ ials@ufu.br
}

\begin{abstract}
Resumo: A localização e a internacionalização de sites são práticas que visam, dentre outros objetivos, (i) atingir ou atrair clientes em novos mercados; e/ou (ii) conferir maior credibilidade e visibilidade à instituição, empresa ou produto a que se destina o seu conteúdo. Em se tratando da internacionalização de sites universitários, ambos os objetivos podem prevalecer, dependendo das metas da instituição, mas geralmente tem havido uma tendência de utilização do inglês como língua franca como forma de divulgar a instituição e atrair alunos de diferentes partes do mundo. Este trabalho apresenta os procedimentos adotados e os resultados da tradução de um site universitário. Utilizando o software Alchemy Catalyst e mediante discussões com a "cliente", então coordenadora do curso, os autores traduziram o site do Curso de Tradução da Universidade Federal de Uberlândia com a finalidade de divulgação do curso para um público internacional leitor em língua inglesa. Os resultados revelam o compromisso firmado entre tradutores e "cliente", bem como procedimentos de maior destaque, como a omissão.
\end{abstract}

Palavras-chave: Internacionalização de site. CAT tool. Tradução de site. Internacionalização da universidade. Site institucional.

\begin{abstract}
Website localization and internationalization are practices that, among other objectives, aim at (i) reaching and attracting clients in new markets; and/or (ii) providing more credibility and visibility to the institution, company or product for which its content is intended. As far as the internationalization of universities' websites is concerned, both goals might be present depending on the institution's objectives, but there has been a tendency to use English as lingua franca as a way to promote the institution at a global level and attract students from different parts of the world. This article reports on the procedures used in and the results of translating a university website. By using the proprietary software Alchemy Catalyst and carrying out discussions with the "client", the then undergraduate program coordinator, the authors translated the website of the Undergraduate Program in Translation at Universidade Federal de Uberlândia aiming at publicizing the program to an Englishspeaking international audience. The results show the commitment between translators and "client", as well as relevant procedures, including omission.
\end{abstract}

Keywords: Website internationalization. CAT tool. Website translation. University internationalization. Institutional site. 


\section{Introdução}

egundo Fernández-Costales (2012, 2010), existem diversos estudos que versam sobre a localização de sites (e.g., JIMÉNEZ-CRESPO, 2013; PYM, 2011) e alguns que analisam a internacionalização de sites de empresas multinacionais (e.g., SINGH;

PEREIRA, 2005); contudo, ainda são incipientes trabalhos que abordem sites institucionais, como é o caso de sites universitários. Na acepção de Fernández-Costales (2012, 2010), a tradução de sites universitários pode ser considerada economicamente eficaz se gerar receitas e benefícios por meio do aumento da visibilidade da instituição, da ampliação de sua capacidade de atrair estudantes estrangeiros e talentos profissionais (e.g., pesquisadores e professores) e de possíveis impactos no ranking internacional das universidades. O referido autor conclui, em seu estudo, que os sites universitários vêm passando por um processo de globalização ou padronização - em vez de localização -, tendo o inglês como língua franca e sendo raros os casos de adaptações para outras línguas, até mesmo no contexto multilinguístico das instituições europeias. Para ele, a internacionalização de sites institucionais como os universitários constitui uma linha de pesquisa interessante em razão de ser permeada por uma tensão entre o global e o 46 local.

Observa-se, portanto, que são incipientes as pesquisas que investigam - seja sob o ponto de vista teórico, seja sob o ponto de vista prático - em que exatamente consiste a internacionalização de um site e quais seriam seus pontos de convergência ou divergência com o que normalmente se denomina de "localização de sites". Como mostra Fernández Costales (2012), os sites vêm sendo traduzidos não para uma localidade específica, mas sim para algumas línguas prioritárias, dentre as quais se destaca o inglês. Além disso, Fernández Costales (op. cit.) afirma também que a tradução de sites nem sempre se dá por meio do uso dos vários recursos tecnológicos disponíveis para a realização de tarefas tradutórias dessa natureza recursos esses geralmente denominados de CAT (computer-aided translation) tools, ou seja, ferramentas de tradução assistida por computador. Nesse contexto, este artigo apresenta uma proposta de tradução inversa (DA SILVA, 2019; DA SILVA, SILVEIRA, 2017) de um site universitário com o aporte de uma ferramenta tecnológica. 


\section{Revisão da Literatura}

Esta seção está divida em duas subseções. Na primeira, abordam-se temáticas relacionadas com a localização e internacionalização de sites. Na segunda, abordam-se questões relativas ao uso de tecnologias na prática tradutória.

\subsection{Localização, Internacionalização e Afins}

Em se tratando de softwares e sites, é comum a utilização de quatro termos conhecidos, em inglês, sob o acrônimo GILT: globalização, internacionalização, localização e tradução. Trata-se de termos que descrevem quatro fenômenos ou processos interligados (JIMÉNEZCRESPO, 2013). Em relação à definição desses termos, Schäler (2007) afirma que, mesmo após mais de duas décadas de localização, ainda não há consenso sobre o significado de globalização (g11n), internacionalização (i18n) e localização (110n) e tampouco sobre a correlação entre esses termos.

A globalização, na perspectiva do termo GILT, pode ser compreendida como

[...] todas as decisões e atividades empresariais necessárias para internacionalizar uma organização tanto em escopo quanto em perspectivas. A globalização é a transformação dos negócios e processos para dar suporte aos clientes em todo o mundo em qualquer idioma, país ou cultura em que eles precisem. ${ }^{1}$ (LISA, 2003, p. 1. Nossa tradução)

A internacionalização, por sua vez, consiste em

[...] remover as particularidades linguísticas das funcionalidades de determinado produto de modo que o suporte ao idioma possa ser adicionado novamente, de forma simples, sem a preocupação de que recursos específicos do idioma sejam um problema ao localizar o produto. $^{2}$ (LISA, 2003, p. 14. Nossa tradução)

Consoante Hartley (2009), a internacionalização inclui garantir, por exemplo, que o conjunto de caracteres (e.g., árabe, português, chinês, russo) necessários em determinada localidade (locale, em inglês) seja exibido corretamente, que os leiautes de teclado sejam suportados, que os números e as datas sejam exibidos em formato correto e que haja, na página ou no campo designado, espaço suficiente para a apresentação do texto junto com o trabalho de arte. A internacionalização, nesse caso, é uma etapa do processo de desenho e desenvolvimento do produto ou serviço, o que se dá, em geral, antes da localização propriamente dita ou concomitantemente a ela.

A localização, de forma geral, seria o "processo de modificação de um produto para uma localidade específica"3 (YUNKER, 2002, p. 17 apud SANDRINI, 2008, p. 3. Nossa tradução). O locale/localidade, neste contexto, entende-se por 
[...] um conjunto de parâmetros utilizados para identificar o idioma, o país e outras preferências do usuário. É a combinação de uma linguagem com uma região geográfica e todas as implicações culturais envolvidas - por exemplo, um país, uma região ou uma cidade. A localidade não é uma cultura; a cultura é mais abrangente, muito mais enraizada e muito menos volátil do que uma localidade. ${ }^{4}$ (SANDRINI, 2008, p. 168. Nossa tradução)

Anastasiou e Schäler (2010, p. 15) apresentam o seguinte quadro comparativo entre internacionalização, localização e globalização.

QUADRO 1 - Diferenças entre internacionalização, localização e globalização

\begin{tabular}{|c|c|c|c|}
\hline & Internacionalização & Localização & Globalização \\
\hline Definição & $\begin{array}{l}\text { Desvinculação da } \\
\text { funcionalidade em } \\
\text { relação a qualquer língua } \\
\text { e conteúdo (dados } \\
\text { linguísticos e culturais) }\end{array}$ & $\begin{array}{l}\text { Adaptação de produtos, } \\
\text { serviços e conteúdos } \\
\text { digitais a um mercado } \\
\text { cultural-linguístico }\end{array}$ & $\begin{array}{l}\text { Estratégia de levar um } \\
\text { produto ou serviço ao } \\
\text { mercado global, o que } \\
\text { envolve vendas e } \\
\text { marketing }\end{array}$ \\
\hline Pessoas envolvidas & $\begin{array}{l}\text { Desenvolvedores de } \\
\text { softwares, produtores e } \\
\text { autores de conteúdos } \\
\text { digitais }\end{array}$ & $\begin{array}{l}\text { Tradutores, revisores, } \\
\text { programadores, gerentes } \\
\text { de projetos, testadores e } \\
\text { distribuidoras }\end{array}$ & $\begin{array}{l}\text { Pessoal de vendas e } \\
\text { marketing }\end{array}$ \\
\hline Etapa & $\begin{array}{l}\text { Desenvolvimento e } \\
\text { desenho de um produto } \\
\text { (conteúdo) ou serviço } \\
\text { digital (pré-requisito para } \\
\text { a localização) }\end{array}$ & $\begin{array}{l}\text { Tradução e adaptação de } \\
\text { textos, interface do } \\
\text { usuário e convenções } \\
\text { culturais }\end{array}$ & $\begin{array}{l}\text { Lançamento, no mercado, } \\
\text { do produto ou serviço } \\
\text { internacionalizado e } \\
\text { localizado }\end{array}$ \\
\hline
\end{tabular}

Fonte: Anastasiou; Schäler (2010, p. 15. Nossa tradução)

A localização surgiu inicialmente para softwares, que pode ser entendido por "todo componente não material de um sistema eletrônico" 5 (SANDRINI, 2008, p. 169. Nossa tradução). Nesse caso, a localização tem por objetivo que os usuários, independentemente da localidade em que estejam, possam utilizar os softwares sem maiores dificuldades (SANDRINI, 2008, p. 169). Trata-se de um processo cujo principal foco, segundo Sandrini (2008, p. 169), reside na funcionalidade. Em outras palavras, o usuário do software na língua-alvo deverá ser capaz de utilizá-lo adequadamente conforme os fins para os quais ele foi projetado. Nesse caso, Sandrini aponta que "as questões de qualidade da linguagem utilizada são, em certa medida, menos críticas" (2008, p. 178).

A localização de site, no entanto, difere-se da localização de software. Segundo Sandrini (2005, 2008), ela nem sempre abrange a questão de funcionalidade, mas, sim, o conteúdo, a informação, uma vez em que muitos sites são mais informativos do que funcionais. São os conteúdos que devem ser localizados para determinada cultura visando que o usuário consiga compreendê-los de forma relevante. Outrossim, um site é muito mais dinâmico em relação a 
um software - recebe atualizações constantemente, além de possuir mais conteúdo multimídia, como imagens e vídeos, que também requerem a localização. ${ }^{6}$

Em se tratando especificamente da localização de sites, Singh e Pereira (2005) identificam cinco graus possíveis, quais sejam:

i. $\quad$ site padronizado: um site para todos os países;

ii. $\quad$ site semilocalizado: um site fornece diversas informações sobre vários países;

iii. $\quad$ site localizado: um site totalmente traduzido para cada país;

iv. $\quad$ site altamente localizado: $u m$ site com traduções mais adaptações específicas para cada país; e

v. site culturalmente customizado: um site inteiramente imerso na cultura-alvo.

Como aponta Pym (2011), apenas os graus "localizado" e "altamente localizado" envolvem tradução no sentido tradicional do termo. Além disso, o autor sugere que existem diversos estágios intermediários entre esses dois graus. A título de exemplo, o autor aponta que é possível haver um site cujas informações gerais sejam traduzidas, mas as informações técnicas específicas, não, tendo em vistas atender a usuários especialistas na parte técnica.

Por fim, vale apontar que existe um tipo especial de localização, ao qual Jiménez-Crespo (2010) se refere como a produção de uma versão neutra de uma língua multinacional. Nesse tipo de localização, existe a internacionalização de uma ou mais línguas que apresentam múltiplas variedades regionais, sendo que, nesse caso, o termo internacionalização admite significado distinto daquele apresentado acima em referência ao estágio de desenvolvimento do produto ou serviço. Conforme aponta o autor, a neutralização ou internacionalização de uma língua é um estágio distinto do processo de localização que ocorre após a etapa de internacionalização na acepção apresentada inicialmente nesta seção.

Quando se adota uma estratégia de utilização de uma linguagem neutra, implicitamente se associa uma língua internacional a uma cultura supranacional, mesmo quando o princípio subjacente à adoção de locales fosse a necessidade de separar línguas das regiões socioculturais e de suas especificidades. Nesse caso, diz Crespo-Jiménez (2010), aplica-se uma definição difusa de língua que separa aspectos linguísticos e cultura, a despeito de todas as línguas serem culturalmente situadas. É o que ocorre, por exemplo, com o uso do inglês como língua franca com a adoção de uma variedade linguística que não obedeceria a fatores geográficos, mas sim à necessidade de uma ferramenta de uso comum para a comunicação internacional 
(FERNÁNDEZ-COSTALES, 2010). Com isso, tem-se uma versão simplificada da "língua matriz", ou seja, tem-se uma versão sem idiomatismos regionais. Chega-se, no caso do inglês, ao que Snell-Hornby (2000, p. 11-28 apud FERNANDEZ-COSTALES, 2010) chama de McEnglish, McLanguage ou Inglês Internacional, no qual há uma redução no escopo estilístico e lexical.

\subsection{Tecnologia e Tradução}

Já em 2002, Lynne Bowker aponta que existe uma miríade de opções tecnológicas disponíveis para auxiliar o trabalho do tradutor. Conforme afirmam Gil e Pym (2010), a tecnologia não é mais uma opção para o profissional, mas sim uma necessidade. Para os autores, hoje é quase que redundância se falar em tradução assistida por computador (em inglês, CAT) porque praticamente todas as traduções atuais são realizadas em computadores, sendo as ferramentas mais revolucionárias aquelas utilizadas praticamente de forma diária, ferramentas de buscas na internet, corretores ortográficos em editores de texto e funções de localizar e substituir ou copiar e colar. O termo CAT tools refere-se a diversas funções, equipamentos e

50 programas que tendem a facilitar o trabalho do tradutor. Inclui, por exemplo, funções de alinhamento, extração de termos, garantia de qualidade e gerenciamento de fluxos de trabalho; além disso, inclui softwares como sistemas de memória de tradução, tradutores automáticos e glossários.

Como explica Hartley (2009), a tecnologia não se refere apenas a ferramentas de hardware e de software. Também abrange coleções de técnicas que permitem a produção de bens e serviços. É o caso, por exemplo, do (i) HTML (HyperText Markup Language, ou seja, Linguagem de Marcação de Hipertexto), uma linguagem padrão que permite a produção de sites e sua leitura em navegadores como o Internet Explorer e o Mozilla Firefox, e do (ii) Unicode, uma forma de armazenamento, processamento e exibição de caracteres em computadores capazes de acomodar letras, ideogramas, números, símbolos e pontuações nas mais diversas línguas, evitando conflitos de codificação entre máquinas operando com sistemas linguísticos distintos.

A despeito de todas as vantagens trazidas pelas CAT tools, como aumento na consistência e produtividade, Gil e Pym (2010) apontam que há também desvantagens. Dentre elas se destacam os altos custos de investimento em uma ferramenta, o que exige uma avaliação de retornos sobre o investimento e a possibilidade de haver uma curva de aprendizagem bastante lenta, o que pode reduzir a produtividade e a efetividade no início da utilização da ferramenta, 
bem como a restrição conceitual do ato tradutório a atividades de mera substituição de textos.

Em se tratando de desvantagens e vantagens, também cabem ponderações éticas, como levantado por Stupiello (2012). Nas palavras da autora:

O modo como são contratados e desenvolvidos projetos de tradução contemporâneos assistidos por ferramentas eletrônicas, como os sistemas de memória, têm promovido mudanças definitivas na maneira como o tradutor atua e em como seu trabalho é reconhecido e remunerado. (STUPIELLO, 2012, p. 89)

Dentre os autores citados por Stupiello (2012) em sua revisão da literatura sobre ética, pode-se citar Pym (1997), que busca favorecer a cooperação entre o tradutor e o cliente. O "tradutor ético", de acordo com o referido autor, "seria aquele que avalia a finalidade da tradução para decidir o que e como traduzir, de forma a maximizar a colaboração com o cliente" (STUPIELLO, 2012, p. 79). Essa colaboração é aqui mencionada porque foi intencionada durante o processo de preparação e tradução do site do Curso de Tradução da Universidade Federal de Uberlândia, conforme será descrito na seção a seguir.

\section{Metodologia}

Esta seção descreve a metodologia adotada para a realização do presente trabalho, que visou à tradução de um site universitário com o aporte de uma ferramenta tecnológica. Mais especificamente, trata-se da tradução do site do Curso de Bacharelado em Tradução da Universidade Federal de Uberlândia (UFU) em sua versão até então disposta em http://www.ileel.ufu.br/tradução (cf. Figura 1). Compete sublinhar que a nova versão apresenta diferenças em relação à que está exibida neste artigo, em função de uma padronização recente nos sites da UFU, conforme se pode observar em http://www.portal.ileel.ufu.br/traducao.

Para que o site possa ser traduzido utilizando uma CAT tool de localização de site, os arquivos que o compõem devem ser adquiridos. Em contato com o webdesigner do site, Fernando Oliveira, o primeiro autor solicitou-lhe o conteúdo, que foi disponibilizado em um pendrive. Vale ressaltar que, nesse caso em particular, embora a aquisição do material necessário tenha sido simples, esse tipo de contato, por vários motivos, nem sempre ocorre dessa forma. Por exemplo, há casos em que o tradutor não consegue entrar em contato com o webdesigner ou este não tem mais o conteúdo disponível ou não o quer disponibilizar. Com isso em mente, cogitou-se também uma segunda forma para obtenção do site, que seria por meio do software HTTrack. Esse software permite o download de sites para um computador 
mantendo a sua estrutura original. Ele é gratuito e pode ser obtido pelo seguinte endereço: https://www.httrack.com.

Figura 1 - Página inicial do site do Curso de Tradução da UFU

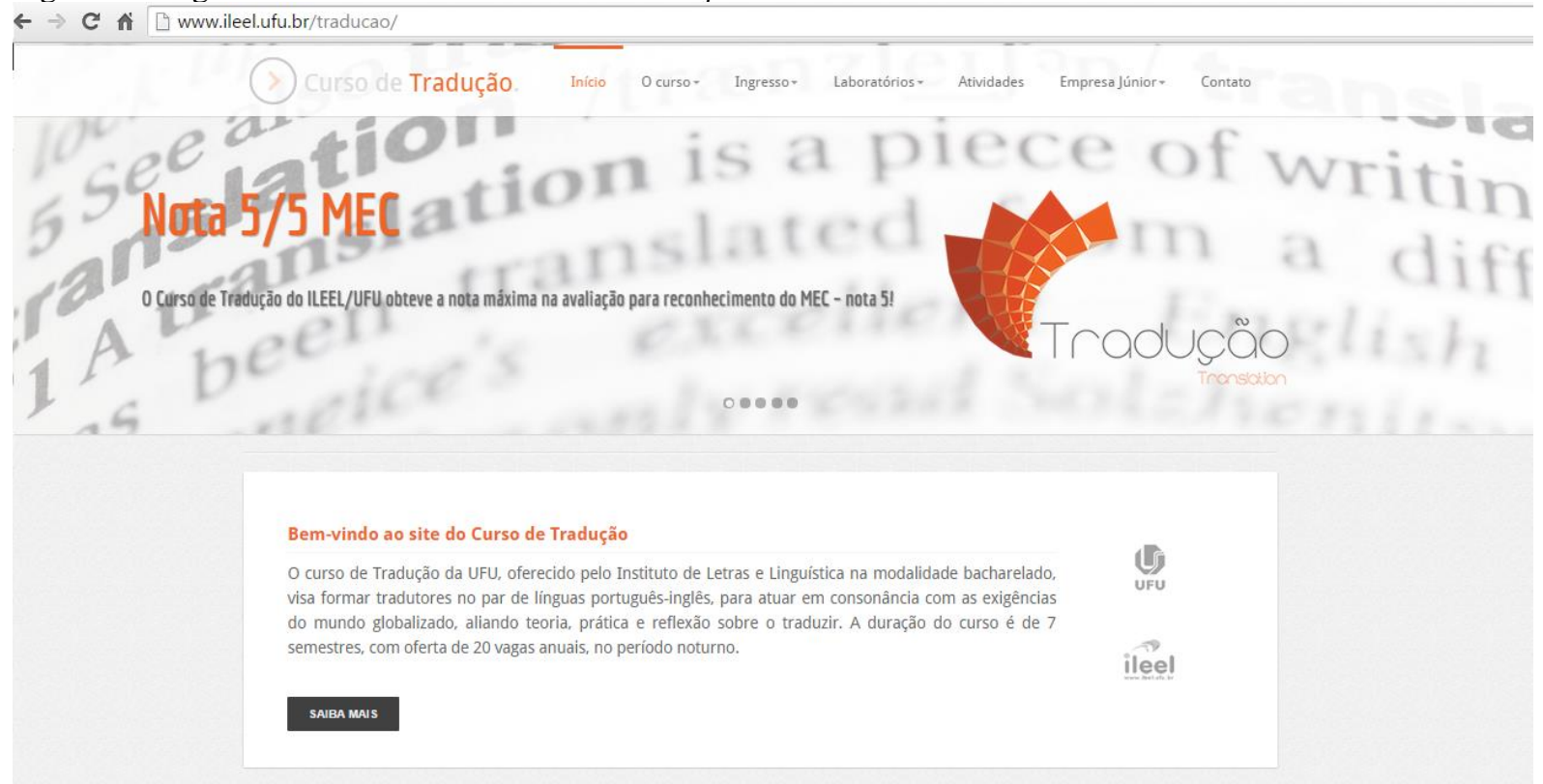

Fonte: instantâneo do site do Curso de Tradução da UFU.

Após a aquisição do conteúdo do site, o passo seguinte foi uma análise desse conteúdo, seguida de um levantamento composto dos elementos que poderiam gerar certa dificuldade na hora de serem traduzidos, elementos passíveis de omissão, elementos passíveis de explicitação e elementos que poderiam ser traduzidos sem grandes dificuldades. Os elementos que causaram maior dificuldade ou incitaram maior reflexão serão mencionados e discutidos na próxima seção.

Usando parte dessa compilação, foi apresentada uma proposta de tradução do site à “cliente", então coordenadora do curso. Após uma discussão sobre o levantamento dos elementos abordados, a cliente concordou com algumas das escolhas apresentadas, discordando, todavia, de outras. A partir desse contato com a "cliente", criou-se uma versão final da proposta de tradução, que serviu de base no momento de se realizar a tradução do site.

A proposta de tradução apresentada à "cliente" e aceita por ela consiste em uma "localização" do terceiro grau apontada por Singh e Pereira (2005), ou seja, tradução de todo o site, porém considerando uma versão internacional da língua inglesa. Tomando esse ponto de partida, esta seção contém a versão final da proposta de tradução, que, por sua vez, contém a estrutura do site dividida em links (i.e., o chamado "mapa do site"), ou seja, somente mostra o 
título de cada página do site, e não o conteúdo completo de cada um. O conteúdo completo de cada página será apresentado mais detalhadamente na próxima seção. Na Figura 2, tem-se, em azul, a proposta dos autores em relação à tradução de cada página e, em vermelho, as intervenções da "cliente".

Como se pode observar na Figura 2, boa parte da proposta de tradução foi aceita pela "cliente", sendo que, em todos os casos, a principal discordância consistiu na omissão de conteúdos do site. Mais especificamente, em quatro das cinco ocorrências de discordâncias, a proposta de tradução dos autores foi recusada pela "cliente" em detrimento da omissão; em um dos cinco casos de discordâncias, a proposta de omissão dos autores foi recusada pela "cliente" em detrimento da tradução de todo o conteúdo.

A CAT tool utilizada na tradução do site foi a Alchemy Catalyst Developer Pro 11.0 Service Pack 1 (11.1). O motivo da escolha do Catalyst foi o seguinte: em contato com os desenvolvedores das CAT tools supracitadas, em que o primeiro autor solicitou uma licença completa (sem limitação quanto às funcionalidades) para a fins de pesquisa, a Alchemy Software Development, desenvolvedora do Alchemy Catalyst, foi a única empresa que respondeu. A empresa gentilmente forneceu uma licença completa de seis meses.

Antes de iniciar o processo de tradução do site, fez-se, conforme mencionado anteriormente, uma leitura do conteúdo em português juntamente com um levantamento do vocabulário específico da área (educação/meio acadêmico) e dos termos que poderiam ter causado maior dificuldade na hora da tradução.

Posteriormente, iniciou-se a tradução do site, que foi realizada a partir de diversas pesquisas. Foram utilizados dicionários eletrônicos e impressos ${ }^{7}$, bem como realizadas consultas frequentes a sites de universidades estrangeiras ${ }^{8}$.

Ao término da tradução de cada página do site, o conteúdo traduzido foi apresentado ao segundo autor, momento em que se discutiram as maiores dificuldades, junto com um esclarecimento de dúvidas e sugestões de melhorias para o site. Em seguida, todo o conteúdo traduzido foi revisado pelo segundo autor, junto com o primeiro autor, havendo uma discussão até que se entrasse num consenso. Após essa etapa, o material traduzido foi enviado, em formato .doc, para um revisor nativo de língua inglesa (estadunidense), cujas intervenções foram aceitas em quase sua totalidade, com exceção de casos em que a releitura da tradução incitou novas perspectivas. As páginas originais e as respectivas traduções finais do site são apresentadas na próxima seção. 
Figura 2 - Mapa do site original juntamente com a proposta de tradução (em azul) e as decisões distintas da "cliente" (em vermelho)

\section{Início \\ - Banners}

- Nota MEC: Omitir ou explicar o que é o MEC e o sistema de notas. - (Omitir)

- Áreas de formação do curso: Traduzir.

- Incentivo à pesquisa: Traduzir.

- Mobilidade Nacional/Internacional: Traduzir. - (Omitir)

○ Empresa júnior - Babel: Traduzir.

O Curso

- Apresentação: Traduzir.

○ Corpo docente: Traduzir.

- Estrutura curricular

- Disciplinas: Traduzir.

- Ementas (PDF): Omitir. - (Traduzir)

- Atividades Complementares (PDF): Explicar sobre as 200 horas necessárias. - (Omitir)

- Fluxograma (PDF): Traduzir.

- Horário das disciplinas (PDF): Traduzir. - (Omitir)

○ Projeto pedagógico (PDF): Omitir.

Ingresso

○ Formas de ingresso: Traduzir.

- Prova de certificação: Mantê-las como no original.

Laboratórios

- Laboratório de Tradução: Traduzir.

- Laboratório de Graduação: Traduzir.

- Laboratório de Línguas: Traduzir.

Atividades

- 2012: Traduzir os textos

- 2011: Traduzir.

- 2010: Traduzir os textos

Empresa Júnior

- Apresentação: Traduzir.

- Serviços: Traduzir.

- Portfólio: Traduzir.

Contato: Traduzir.

Elaboração: Leonardo Penha Mesquita.

Vale destacar que, para a tradução do site, assumiu-se como objetivo de internacionalização a promoção de maior visibilidade ao Curso de Tradução da Universidade Federal de Uberlândia. Tendo isso em mente, a tradução não buscou um público-alvo internacional constituído por potenciais estudantes do curso, mas sim formado por pesquisadores e professores dos estudos da tradução interessados na formação de tradutores em nível superior e nos seus desdobramentos em países como o Brasil. Adotou-se, na tradução, o 
inglês padrão, assumido como condizente com o tipo de instituição de que trata o site (ou seja, uma instituição que trabalha com a linguagem em um contexto de ensino superior).

\section{Tradução comentada do site}

Cada quadro a seguir representa uma página do site e está dividido em três colunas que representam, nesta ordem: (i) segmento (número de identificação para fins de referência ao longo do texto); (ii) original (texto original do site); e (iii) tradução (texto de chegada em inglês correspondente ao texto apresentado na segunda coluna). Ao todo, foram processados 116 segmentos.

Nas análises que seguem aos quadros, atém-se aos trechos que por alguma razão mais se destacam, sobretudo no que diz respeito a problemas de tradução e necessidade de omissão e/ou explicitação ou adição de informações. Para as análises, optou-se por concentrá-las por temática ao final da apresentação de todos os quadros, em vez de se falar de aspectos específicos de cada um deles. 
QUADRO 2 - Página Inicial

\begin{tabular}{|c|c|c|}
\hline Segmento & Original & Tradução \\
\hline 1 & Nota 5/5 MEC & Omitido \\
\hline 2 & $\begin{array}{l}\text { O Curso de Tradução do ILEEL/UFU obteve } \\
\text { a nota máxima na avaliação para } \\
\text { reconhecimento do MEC - nota 5! }\end{array}$ & Omitido \\
\hline 3 & Áreas de formação do curso & Program Training Areas \\
\hline 4 & $\begin{array}{l}\text { Tradução de textos gerais, Tradução de textos } \\
\text { técnico-científicos, Tradução de textos } \\
\text { midiáticos, Tradução audiovisual, Tradução } \\
\text { literária, Interpretação, Revisão de textos. }\end{array}$ & $\begin{array}{l}\text { Translation of general, technical, scientific, } \\
\text { and media texts; audiovisual translation; } \\
\text { literary translation; interpretation and } \\
\text { proofreading. }\end{array}$ \\
\hline 5 & Incentivo à Pesquisa & Research Support \\
\hline 6 & $\begin{array}{l}\text { Desenvolvimento de pesquisas de iniciação } \\
\text { científica nas áreas da tradução, com } \\
\text { oportunidade de bolsas das agências de } \\
\text { fomento. }\end{array}$ & $\begin{array}{l}\text { Undergraduate research development in } \\
\text { translation fields, with opportunity for } \\
\text { financial aid from development agencies. }\end{array}$ \\
\hline 7 & Mobilidade Nacional e Internacional & Omitido \\
\hline 8 & $\begin{array}{l}\text { Participação em Programas de Mobilidade e } \\
\text { de Convênios de Cooperação, estabelecidos } \\
\text { entre a UFU e outras universidades, nacionais } \\
\text { e internacionais. }\end{array}$ & Omitido \\
\hline 9 & Empresa Júnior - Babel Traduções & Junior Enterprise - Babel Traduções \\
\hline 10 & $\begin{array}{l}\text { Realização de trabalhos de tradução e revisão } \\
\text { de textos segundo os parâmetros profissionais } \\
\text { da área. }\end{array}$ & $\begin{array}{l}\text { Translation and proofreading following the } \\
\text { professional standards of the translation field. }\end{array}$ \\
\hline 11 & Bem-vindo ao site do Curso de Tradução & $\begin{array}{l}\text { Welcome to the Bachelor's Degree in } \\
\text { Translation Program }\end{array}$ \\
\hline 12 & $\begin{array}{l}\text { O Curso de Tradução da UFU, oferecido pelo } \\
\text { Instituto de Letras e Linguística na } \\
\text { modalidade bacharelado, visa formar } \\
\text { tradutores no par de línguas português-inglês, } \\
\text { para atuar em consonância com as exigências } \\
\text { do mundo globalizado, aliando teoria, prática } \\
\text { e reflexão sobre o traduzir. A duração do curso } \\
\text { é de } 7 \text { semestres, com oferta de } 20 \text { vagas } \\
\text { anuais, no período noturno. }\end{array}$ & $\begin{array}{l}\text { The Bachelor's Degree in Translation } \\
\text { Program is offered by the Languages and } \\
\text { Linguistics Institute (ILEEL) of Universidade } \\
\text { Federal de Uberlândia (UFU), Minas Gerais, } \\
\text { Brazil. It aims to train translators in the } \\
\text { Portuguese-English language pair so that they } \\
\text { can meet the demands of the globalized world, } \\
\text { combining theory, practice and reasoning } \\
\text { about translation. The program is } 3.5 \text { years } \\
\text { long, and it offers } 20 \text { places at part-time } \\
\text { period (night). }\end{array}$ \\
\hline 13 & Saiba mais & More information \\
\hline 14 & Videos & Videos \\
\hline 15 & Aula inaugural do Curso de Tradução - 2010 & Inaugural Class - 2010 \\
\hline 16 & $\begin{array}{l}\text { Babel Traduções - Empresa Júnior do Curso } \\
\text { de Tradução }\end{array}$ & Babel Traduções - Junior Enterprise \\
\hline 17 & Workshop - Tradução para dublagem & Workshop - Translation for Dubbing \\
\hline 18 & $\begin{array}{l}\text { Tecnologias de tradução utilizadas em nosso } \\
\text { curso }\end{array}$ & $\begin{array}{l}\text { Computer-Aided Translation Tools used in } \\
\text { our program }\end{array}$ \\
\hline
\end{tabular}

Elaboração: Leonardo Penha Mesquita. 
QUADRO 3 - Página de Apresentação

\begin{tabular}{|c|c|c|}
\hline Segmento & Original & Tradução \\
\hline 19 & Apresentação & Overview \\
\hline 20 & $\begin{array}{l}\text { O Curso de Tradução da UFU, criado no } \\
\text { âmbito do REUNI, teve início em 2010, sendo } \\
\text { oferecido pelo Instituto de Letras e } \\
\text { Linguística - ILEEL. O Curso de Tradução } \\
\text { visa formar profissionais com sólidos } \\
\text { conhecimentos das línguas maternas } \\
\text { (português) e estrangeiras (inglês) e suas } \\
\text { respectivas culturas, conscientes da } \\
\text { integração entre os conhecimentos teóricos e } \\
\text { a prática tradutória, capacitados para realizar } \\
\text { traduções de diferentes gêneros (técnico- } \\
\text { científico, audiovisual, literário etc.). }\end{array}$ & $\begin{array}{l}\text { The Bachelor's Degree in Translation } \\
\text { Program of Universidade Federal de } \\
\text { Uberlândia was created in } 2010 \text { and is offered } \\
\text { by the Language and Linguistics Institute } \\
\text { (ILEEL). The program aims to train } \\
\text { professionals with solid knowledge on both } \\
\text { native language (Portuguese) and foreign } \\
\text { language (English), as well as their respective } \\
\text { cultures. Another goal is to raise the } \\
\text { professional's awareness of the connection } \\
\text { between theoretical knowledge and } \\
\text { translation practice so they are able to handle } \\
\text { translations in different genres (technical, } \\
\text { scientific, audiovisual, literary, etc.). }\end{array}$ \\
\hline 21 & $\begin{array}{l}\text { Tendo em vista o mercado em franca } \\
\text { expansão para os tradutores, cuja formação } \\
\text { deve corresponder às várias competências } \\
\text { exigidas deste profissional, o curso enfoca a } \\
\text { tradução (inglês-português e português- } \\
\text { inglês) de vários tipos de textos, com o auxílio } \\
\text { da tecnologia e da reflexão teórica cerca dos } \\
\text { estudos da tradução. }\end{array}$ & $\begin{array}{l}\text { Bearing in mind the booming translation job } \\
\text { market, which requires training to develop the } \\
\text { skills translators need, the Translation } \\
\text { Program approaches the translation (English- } \\
\text { Portuguese and Portuguese-English) of } \\
\text { several types of texts, with the aid of } \\
\text { technology and theoretical reasoning. }\end{array}$ \\
\hline 22 & $\begin{array}{l}\text { O objetivo primordial do curso é, portanto, a } \\
\text { formação profissional do tradutor, com vistas } \\
\text { a uma prática adequada às necessidades da } \\
\text { sociedade atual. }\end{array}$ & $\begin{array}{l}\text { The program's main of objective is training } \\
\text { translators with a view to a proper practice } \\
\text { that meets the society's needs. }\end{array}$ \\
\hline 23 & $\begin{array}{l}\text { O curso tem a duração de } 7 \text { semestres, seu } \\
\text { regime é semestral, e sua oferta é de } 20 \text { vagas } \\
\text { anuais, no período noturno. }\end{array}$ & $\begin{array}{l}\text { The program takes } 3.5 \text { years to complete and } \\
\text { its period of study is semester-long. Every } \\
\text { year, } 20 \text { places are offered at part-time period } \\
\text { (night). }\end{array}$ \\
\hline
\end{tabular}

Elaboração: Leonardo Penha Mesquita. 
QUADRO 4 - Página de Disciplinas (compilado com todas as páginas que contêm as disciplinas do curso)

\begin{tabular}{|c|c|c|}
\hline Segmento & Original & Tradução \\
\hline 24 & $\begin{array}{l}\text { Estudos do texto: coesão, coerência e } \\
\text { tipologia }\end{array}$ & $\begin{array}{l}\text { Text Studies: Cohesion, Coherence, and } \\
\text { Typology }\end{array}$ \\
\hline 25 & Língua inglesa: estrutura e uso & English Language: Structure and Use \\
\hline 26 & Introdução aos estudos da tradução & Introduction to Translation Studies \\
\hline 27 & Do latim ao português & From Latin to Portuguese \\
\hline 28 & Leituras do texto literário & Literature \\
\hline 29 & Tipos e gêneros textuais & Text Types and Genres \\
\hline 30 & $\begin{array}{l}\text { Língua inglesa: idiomaticidade e } \\
\text { convencionalidade }\end{array}$ & $\begin{array}{l}\text { English Language: Idiomaticity and } \\
\text { Conventionality }\end{array}$ \\
\hline 31 & Tradução comentada & Annotated Translation \\
\hline 32 & Procedimentos técnicos da tradução & Translation Methods \\
\hline 33 & Estudo dos gêneros literários & Study of Literary Genres \\
\hline 34 & Produção criativa de textos & Writing Creative Texts \\
\hline 35 & $\begin{array}{l}\text { Língua inglesa: análise contrastiva em língua } \\
\text { inglesa }\end{array}$ & English Language: Contrastive Analysis \\
\hline 36 & Prática de tradução: textos gerais & Translation Practice: General Texts \\
\hline 37 & Teorias contemporâneas da tradução & Contemporary Translation Theories \\
\hline 38 & Literaturas de expressão em língua inglesa & English Literature \\
\hline 39 & Português para tradutores & Portuguese for Translators \\
\hline 40 & Língua inglesa: redação em língua inglesa & English Language: Writing \\
\hline 41 & $\begin{array}{l}\text { Prática de tradução: textos técnicos e } \\
\text { científicos }\end{array}$ & $\begin{array}{l}\text { Translation Practice: Technical and Scientific } \\
\text { Texts }\end{array}$ \\
\hline 42 & $\begin{array}{l}\text { Treinamento de tradutores e novas } \\
\text { ferramentas I }\end{array}$ & $\begin{array}{l}\text { Translation Training and New Computer- } \\
\text { Assisted Translation Tools I }\end{array}$ \\
\hline 43 & Metodologia de pesquisa em tradução & Research Methodology in Translation \\
\hline 44 & Revisão de textos & Proofreading \\
\hline 45 & $\begin{array}{l}\text { Língua inglesa: estudos descritivos e } \\
\text { lingüística de corpus }\end{array}$ & $\begin{array}{l}\text { English Language: Descriptive Studies and } \\
\text { Corpus Linguistics }\end{array}$ \\
\hline 46 & Prática de tradução: textos audiovisuais & Translation Practice: Audiovisual Texts \\
\hline 47 & $\begin{array}{l}\text { Treinamento de tradutores e novas } \\
\text { ferramentas II }\end{array}$ & $\begin{array}{l}\text { Translation Training and New Computer- } \\
\text { Assisted Translation Tools II }\end{array}$ \\
\hline 48 & Tradução para a língua inglesa I & Translating into English Language I \\
\hline 49 & Terminologia aplicada à tradução & Terminology Applied to Translation \\
\hline 50 & Fundamentos da interpretação & Introduction to Interpreting Studies \\
\hline 51 & Prática de tradução: textos literários & Translation Practice: Literary Texts \\
\hline 52 & Projeto de monografia & Final Paper Project \\
\hline 53 & Tradução para a língua inglesa II & Translating into English Language II \\
\hline 54 & Disciplina OPTATIVA & OPTIONAL Course \\
\hline 55 & Monografia & Final Paper \\
\hline
\end{tabular}

Elaboração: Leonardo Penha Mesquita. 
QUADRO 5 - Página de Ingresso

\begin{tabular}{|c|c|c|}
\hline Segmento & Original & Tradução \\
\hline 56 & Formas de ingresso & Admissions \\
\hline 57 & $\begin{array}{l}\text { Informações sobre o ingresso no Curso de } \\
\text { Tradução }\end{array}$ & $\begin{array}{l}\text { Information about admission to the Bachelor's } \\
\text { Degree in Translation Program }\end{array}$ \\
\hline 58 & $\begin{array}{l}\text { O Curso de Tradução da UFU é uma } \\
\text { graduação, ofertada na modalidade presencial, } \\
\text { bacharelado (português-inglês) e dura } 7 \\
\text { semestres. }\end{array}$ & Omitido \\
\hline 59 & $\begin{array}{l}\text { Para ingresso no curso, seguem-se as mesmas } \\
\text { regras de ingresso a qualquer curso desta } \\
\text { universidade. }\end{array}$ & $\begin{array}{l}\text { The admissions to the Translation Program } \\
\text { follow the same rules as other programs of } \\
\text { Universidade Federal de Uberlândia. }\end{array}$ \\
\hline 60 & $\begin{array}{l}\text { Como até o presente momento, a UFU aderiu } \\
\text { totalmente ao ENEM em substituição ao } \\
\text { vestibular, essa se tornou a principal forma de } \\
\text { ingresso, e o Curso de Tradução oferece quinze } \\
\text { vagas nessa modalidade. }\end{array}$ & $\begin{array}{l}\text { As of now, UFU has completely adopted } \\
\text { ENEM (National High School Exam), that has } \\
\text { become the main form of admission to the } \\
\text { Translation Program, which offers } 20 \text { places } \\
\text { once a year. }\end{array}$ \\
\hline 61 & $\begin{array}{l}\text { As outras cinco vagas são destinadas ao } \\
\text { processo de ingresso de forma seriada, o Paaes, } \\
\text { destinado aos alunos de escola pública. }\end{array}$ & Omitido \\
\hline 62 & $\begin{array}{l}\text { O ingresso ao curso, através desses processos, } \\
\text { acontece apenas uma vez por ano, totalizando, } \\
\text { portanto, } 20 \text { vagas anuais. }\end{array}$ & Omitido \\
\hline 63 & $\begin{array}{l}\text { A UFU ainda adota outras formas de ingresso } \\
\text { para as vagas remanescentes (vagas oriundas } \\
\text { de desistência, falecimento, abandono, etc...), } \\
\text { entre elas: reingresso, transferência interna, } \\
\text { transferência externa e, por último, portador de } \\
\text { diploma( uma opção interessante para quem já } \\
\text { tem curso superior). }\end{array}$ & $\begin{array}{l}\text { UFU still uses other forms of admission to the } \\
\text { remaining places (which result from waiver, } \\
\text { death, abandonment, etc.) including: } \\
\text { readmission, internal and external transfer, and } \\
\text { diploma carier (an interesting option for those } \\
\text { who possess an undergraduate diploma). }\end{array}$ \\
\hline 64 & $\begin{array}{l}\text { Demais informações a respeito das formas de } \\
\text { ingresso no curso, consulte o site } \\
\text { www.ingresso.ufu.br. }\end{array}$ & $\begin{array}{l}\text { For further information regarding forms of } \\
\text { admission, please visit www.ingresso.ufu.br } \\
\text { (Portuguese-only). }\end{array}$ \\
\hline 65 & Agora atenção à informação abaixo: & Attention to the information below: \\
\hline 66 & $\begin{array}{l}\text { No entanto, antes disso, assim como em outros } \\
\text { seis cursos na UFU, para o ingresso é preciso } \\
\text { que o candidato faça uma prova de } \\
\text { certificação. }\end{array}$ & $\begin{array}{l}\text { In order to be admitted, the student must take a } \\
\text { proficiency test. }\end{array}$ \\
\hline 67 & $\begin{array}{l}\text { Esta prova de certificação ocorre duas vezes } \\
\text { por ano (em } 2011 \text { houve uma em maio e uma } \\
\text { em outubro, em } 2012 \text { houve uma prova em } \\
\text { maio, e uma em novembro, em } 2013 \text { haverá, } \\
\text { novamente em maio). }\end{array}$ & Omitido \\
\hline 68 & $\begin{array}{l}\text { Trata-se de uma prova escrita (português- } \\
\text { inglês), realizada antes da seleção } \\
\text { propriamente dita, cuja finalidade é verificar a } \\
\text { proficiência em inglês e as habilidades em } \\
\text { tradução do candidato. }\end{array}$ & $\begin{array}{l}\text { It is a written test (Portuguese-English) offered } \\
\text { twice a year and held before the selection itself, } \\
\text { whose purpose is to check the candidate's } \\
\text { proficiency in English and translation skills. }\end{array}$ \\
\hline 69 & $\begin{array}{l}\text { Sobre a prova de habilidade, e demais } \\
\text { informações a respeito das formas de ingresso } \\
\text { no curso, consulte o s site } \\
\text { http://www.ingresso.ufu.br/certificacao. }\end{array}$ & $\begin{array}{l}\text { For further information regarding the } \\
\text { proficiency test and the forms of admission, } \\
\text { please } \\
\text { http://www.ingresso.ufu.br/certificacao visit } \\
\text { (Portuguese-only). }\end{array}$ \\
\hline 70 & Demais informações: www.ingresso.ufu.br & Omitido \\
\hline
\end{tabular}

Elaboração: Leonardo Penha Mesquita. 
QUADRO 6 - Página do Laboratório de Tradução

\begin{tabular}{c|l|l}
\hline Segmento & \multicolumn{1}{c|}{ Original } & \multicolumn{1}{c}{ Tradução } \\
\hline 71 & Laboratório de Tradução & Translation Laboratory \\
\hline 72 & Sobre o laboratório & About the Laboratory \\
\hline 73 & $\begin{array}{l}\text { O Laboratório de Tradução visa à formação } \\
\text { específica e continuada dos alunos do Curso de } \\
\text { Tradução, bem como de local para a prática da } \\
\text { tradução assistida por computador, em } \\
\text { consonância com as modernas técnicas de } \\
\text { traduzir. }\end{array}$ & $\begin{array}{l}\text { The Translation Laboratory aims at specific } \\
\text { and ongoing training of the Translation } \\
\text { Practice of computer-assisted translation, in } \\
\text { line with modern translation techniques. }\end{array}$ \\
\hline 74 & $\begin{array}{l}\text { Possui 10 computadores, com acesso à internet, } \\
\text { mesa para reuniões e armários modulares para o } \\
\text { arquivamento de material impresso e } \\
\text { multimídia. }\end{array}$ & $\begin{array}{l}\text { The laboratory has 15 computers with } \\
\text { internet access, a meeting table, and } \\
\text { modular cabinets for filing printed and } \\
\text { multimedia contents. }\end{array}$ \\
\hline
\end{tabular}

Elaboração: Leonardo Penha Mesquita.

QUADRO 7 - Página do Laboratório de Graduação

\begin{tabular}{c|l|l}
\hline Segmento & \multicolumn{1}{c|}{ Original } & \multicolumn{1}{c}{ Tradução } \\
\hline 75 & Laboratório de Graduação & Undergraduate Laboratory \\
\hline 76 & Sobre o laboratório & About the Laboratory \\
\hline 77 & $\begin{array}{l}\text { O Laboratório de Graduação é uma sala de aula } \\
\text { equipada com 30 computadores, distribuídos } \\
\text { em posições que podem ser ocupadas, cada } \\
\text { uma, por um ou dois alunos, em aulas que } \\
\text { necessitem do uso de recursos tecnológicos. }\end{array}$ & $\begin{array}{l}\text { The Undergraduate Laboratory is a } \\
\text { classroom equipped with 30 computers } \\
\text { arranged in such a way that each can be used } \\
\text { by one or two students at the same time, } \\
\text { during classes that require the use of } \\
\text { technological resources. }\end{array}$ \\
\hline 78 & $\begin{array}{l}\text { Sua configuração permite ao professor } \\
\text { acompanhar e gerenciar, em computador a ele } \\
\text { destinado, as atividades desempenhadas pelos } \\
\text { alunos, em tempo real. }\end{array}$ & $\begin{array}{l}\text { The lecturer can monitor and manage the } \\
\text { activities developed by the students, in real } \\
\text { time, on his or her own computer. }\end{array}$ \\
\hline $\begin{array}{l}\text { Além do uso para aulas, o laboratório pode ser } \\
\text { destinado a cursos técnicos, oficinas, palestras, } \\
\text { e demais formas de interação acadêmica. }\end{array}$ & $\begin{array}{l}\text { Besides classroom use, the laboratory may } \\
\text { be used for technical courses, workshops, } \\
\text { lectures, and other forms of academic } \\
\text { interaction. }\end{array}$ \\
\hline
\end{tabular}

Elaboração: Leonardo Penha Mesquita. 
QUADRO 8 - Página do Laboratório de Línguas

\begin{tabular}{c|l|l}
\hline Segmento & \multicolumn{1}{c|}{ Original } & \multicolumn{1}{c}{ Tradução } \\
\hline 80 & Laboratório de Línguas & Languages Laboratory \\
\hline 81 & Sobre o laboratório & About the Laboratory \\
\hline 82 & $\begin{array}{l}\text { O Laboratório de Línguas é climatizado e } \\
\text { informatizado, com recursos tecnológicos de } \\
\text { última geração, com acesso à internet, } \\
\text { armazenamento e recuperação de arquivos } \\
\text { digitais, sessões individuais ou coletivas, } \\
\text { gerenciadas por dois módulos de } \\
\text { funcionamento independente e simultâneo. } \\
\text { conditioned and computerized. It features } \\
\text { the latest technological resources, internet } \\
\text { access, storage and retrieval of digital files, } \\
\text { and resources for individual or collective } \\
\text { sessions managed by two operating modules } \\
\text { that work independently } \\
\text { simultaneously. }\end{array}$ \\
\hline 83 & $\begin{array}{l}\text { Ele ainda conta com um acervo de filmes e } \\
\text { documentários, em VHS ou mídia digitais, } \\
\text { músicas com a transcrição de letras, exercícios } \\
\text { de fonética, entre outros. }\end{array}$ & $\begin{array}{l}\text { It also has a collection of films and } \\
\text { documentaries on VHS or digital media, } \\
\text { music with lyrics transcripts, phonetic } \\
\text { exercises, among others. }\end{array}$ \\
\hline $\begin{array}{l}\text { Além disso, o LABLING possui ferramentas de } \\
\text { última geração, tais como câmara de } \\
\text { documentos, projeção de sites de internet e de } \\
\text { arquivos audiovisuais em vídeo, estáticos ou em } \\
\text { movimento, em qualquer formato. }\end{array}$ & $\begin{array}{l}\text { In addition, the Languages Laboratory has } \\
\text { cutting-edge tools such as document camera, } \\
\text { projection of internet websites and } \\
\text { audiovisual archives of static or motion } \\
\text { videos, in any format. }\end{array}$ \\
\hline
\end{tabular}

Elaboração: Leonardo Penha Mesquita.

QUADRO 9 - Página das Atividades 2012

\begin{tabular}{c|l|l}
\hline Segmento & \multicolumn{1}{c}{ Original } & \multicolumn{1}{c}{ Tradução } \\
\hline 85 & Atividades 2012 & Activities in 2012 \\
\hline 86 & $\begin{array}{l}\text { "O processo da dublagem brasileira: tradução, } \\
\text { sincronização e discurso oral" }\end{array}$ & $\begin{array}{l}\text { "The Brazilian Dubbing Process: } \\
\text { Translation, Synchronization, and Oral } \\
\text { Speech" }\end{array}$ \\
\hline 87 & $\begin{array}{l}\text { A coordenação do Curso de Tradução } \\
\text { promoveu um workshop intitulado "O processo } \\
\text { da dublagem brasileira: tradução, sincronização } \\
\text { e discurso oral", ministrado pela professora } \\
\text { Dilma Machado, tradutora, dubladora e e } \\
\text { professora especialista pela PUC-Rio. }\end{array}$ & $\begin{array}{l}\text { The } \\
\text { workshop entitled "The Brazilian Dubbing } \\
\text { Process: Translation, Synchronization, and } \\
\text { Oral Speech" conducted by Dilma Machado, } \\
\text { a translator, voice actress, and professor at } \\
\text { PUC-Rio. }\end{array}$ \\
\hline 88 & $\begin{array}{l}\text { O evento foi realizado no dia 25 de maio de } \\
\text { 2012 e contou com a participação de discentes } \\
\text { e docentes do Curso de Tradução. }\end{array}$ & $\begin{array}{l}\text { The workshop was held on May 25th, 2012, } \\
\text { and attended by students and staff of the } \\
\text { Translation Program. }\end{array}$ \\
\hline
\end{tabular}

Elaboração: Leonardo Penha Mesquita. 
QUADRO 10 - Página das Atividades 2011

\begin{tabular}{|c|c|c|}
\hline Segmento & Original & Tradução \\
\hline 89 & Atividades 2011 & Activities in 2011 \\
\hline 90 & Minicurso de Legendagem & Short Course in Subtitling \\
\hline 91 & $\begin{array}{l}\text { A coordenação do Curso de Tradução } \\
\text { organizou um minicurso de legendagem, } \\
\text { ministrado pelos alunos do curso Alexandre } \\
\text { Mendonça Peres e Lygia Caroline Alves. }\end{array}$ & $\begin{array}{l}\text { The Translation Program promoted a short } \\
\text { course in subtitling, conducted by students } \\
\text { Alexandre Mendonça Peres and Lygia } \\
\text { Caroline Alves. }\end{array}$ \\
\hline 92 & $\begin{array}{l}\text { O evento foi realizado no período } 24 \text { a } 26 \text { de } \\
\text { maio de } 2011 \text {, e contou com a participação de } \\
\text { discentes e docentes do Curso de Tradução. }\end{array}$ & $\begin{array}{l}\text { The course was held from May 24th through } \\
\text { 26th, 2011, and was attended by students } \\
\text { and staff of the Translation Program. }\end{array}$ \\
\hline 93 & $\begin{array}{l}\text { Posteriormente, em } 01 \text { de julho de } 2011 \text {, este } \\
\text { mesmo minicurso foi ofertado para alunos do } \\
\text { Curso de Letras. }\end{array}$ & $\begin{array}{l}\text { On July 1st, it was offered to Language and } \\
\text { Literature Program students. }\end{array}$ \\
\hline 94 & Minicurso de Audiodescrição e Legendagem & $\begin{array}{l}\text { Short Course in Audio Description and } \\
\text { Subtitling }\end{array}$ \\
\hline 95 & $\begin{array}{l}\text { A coordenação do Curso de Tradução } \\
\text { organizou um minicurso de audiodescrição e } \\
\text { legendagem para surdos e ensudercidos, } \\
\text { ministrado pelas alunas do curso Laurieny da } \\
\text { Costa Vilela, Karoline Izabella de Oliveira e } \\
\text { Natália Fonseca da Silva, após terem realizado } \\
\text { treinamento na Universidade Estadual do } \\
\text { Ceará, com o grupo coordenado pela Profa. } \\
\text { Vera Santiago. }\end{array}$ & $\begin{array}{l}\text { The Translation Program promoted a short } \\
\text { course of audio description and subtitling for } \\
\text { the deaf and hard of hearing, conducted by } \\
\text { students Laurieny da Costa Vilela, Karoline } \\
\text { Izabella de Oliveira and Natália Fonseca da } \\
\text { Silva after they had attended a training at } \\
\text { Universidade Estadual do Ceará, with a } \\
\text { group coordinated by Professor Vera } \\
\text { Santiago. }\end{array}$ \\
\hline 96 & $\begin{array}{l}\text { O evento foi realizado no período } 14 \text { a } 17 \text { de } \\
\text { junho de } 2011 \text { e contou com a participação de } \\
\text { discentes e docentes do Curso de Tradução. }\end{array}$ & $\begin{array}{l}\text { The course was held from June 14th through } \\
17 \text { th and was attended by students and staff } \\
\text { of the Translation Program. }\end{array}$ \\
\hline 97 & Viagem Técnica ao Rio de Janeiro & Technical Visit to Rio de Janeiro \\
\hline 98 & $\begin{array}{l}\text { Os alunos do Curso de Tradução, em viagem } \\
\text { organizada pela coordenação do curso e por } \\
\text { seus docentes, realizaram visitas técnicas junto } \\
\text { às ilhas de legendagem e dublagem, às } \\
\text { instituições de apoio à tradução, assim como a } \\
\text { instituição formadora de tradutores na cidade do } \\
\text { Rio de Janeiro. }\end{array}$ & $\begin{array}{l}\text { The Translation Program promoted a } \\
\text { technical visit to subtitling and dubbing } \\
\text { agencies, translation support institutions, } \\
\text { and a translation training institution in Rio } \\
\text { de Janeiro, Brazil. }\end{array}$ \\
\hline 99 & $\begin{array}{l}\text { A viagem ocorreu em agosto de } 2011 \text {, tendo } \\
\text { como principais atividades: palestra com a } \\
\text { tradutora Mônika Pecegueiro do Amaral, } \\
\text { especialista em legendas para cinema; palestra } \\
\text { com os professores do Curso de Tradução da } \\
\text { PUC-Rio, Prof Dr Drárcia Martins, Maria } \\
\text { Paula Frota, Paulo Henriques Britto; visita "in } \\
\text { loco" aos estúdios Gemini Media } \\
\text { (Legendagem) e Cinevídeo (dublagem), à } \\
\text { ABRATES (Associação Brasileira de } \\
\text { Tradutores) e ao SINTRA (Sindicato dos } \\
\text { Tradutores). }\end{array}$ & $\begin{array}{l}\text { The visit took place in August and its main } \\
\text { activities included: a lecture with translator } \\
\text { Mônika Pecegueiro do Amaral, who is } \\
\text { specialized in subtitles for movies; a lecture } \\
\text { with staff of the Translation Program from } \\
\text { PUC-Rio, Professor Marcia Martins, PhD, } \\
\text { Maria Paula Frota, and Paulo Henriques } \\
\text { Britto; a visit to the Gemini Media } \\
\text { (subtitling) and Cinevídeo (dubbing) } \\
\text { studios, as well as ABRATES (Brazilian } \\
\text { Association of Translators), and SINTRA } \\
\text { (Translators' Union). }\end{array}$ \\
\hline
\end{tabular}

Elaboração: Leonardo Penha Mesquita. 
QUADRO 11 - Página das Atividades 2010

\begin{tabular}{|c|c|c|}
\hline Segmento & Original & Tradução \\
\hline 100 & Atividades 2010 & Activities in 2012 \\
\hline 101 & Aula Inaugural do Curso de Tradução & Inaugural Class \\
\hline 102 & $\begin{array}{l}\text { A data escolhida para a aula inaugural do curso } \\
\text { foi o dia } 30 \text { de setembro, data em que se } \\
\text { comemora o Dia do Tradutor. }\end{array}$ & $\begin{array}{l}\text { The date chosen for the inaugural class of } \\
\text { the Bachelor's Degree in Translation } \\
\text { Program was September 30th, which is } \\
\text { International Translator's Day. }\end{array}$ \\
\hline 103 & $\begin{array}{l}\text { Para falar do tema Tradução Juramentada, foi } \\
\text { convidado o professor Dr. Francis Henrik } \\
\text { Aubert, Professor Titular da USP, Doutor em } \\
\text { Linguística e Tradutor Juramentado de } \\
\text { norueguês, inglês e português. }\end{array}$ & $\begin{array}{l}\text { Francis Henrik Aubert, Professor at USP, } \\
\text { PhD in Linguistics and sworn translator in } \\
\text { Norwegian, English and Portuguese, was } \\
\text { invited to speak on the topic of Sworn } \\
\text { Translations. }\end{array}$ \\
\hline 104 & $\begin{array}{l}\text { O evento contou com a participação dos alunos } \\
\text { e professores do curso, além de docentes e } \\
\text { discentes do Instituto de Letras e Linguística e } \\
\text { demais interessados no tema. }\end{array}$ & $\begin{array}{l}\text { The event was attended by students and staff } \\
\text { of the Translation Program, of the } \\
\text { Languages and Linguistics Institute, and by } \\
\text { people interested in the topic. }\end{array}$ \\
\hline 105 & $\begin{array}{l}\text { V Congresso Ibero-Americano de Tradução e } \\
\text { Interpretação - CIATI }\end{array}$ & $\begin{array}{l}\text { V Ibero-American Congress of Translation } \\
\text { and Interpretation - CIATI }\end{array}$ \\
\hline 106 & $\begin{array}{l}\text { Os alunos do Curso de Tradução, em viagem } \\
\text { organizada pela coordenação do curso, } \\
\text { participaram do V Congresso Ibero-Americano } \\
\text { de Tradução e Interpretação - CIATI em São } \\
\text { Paulo, capital, durante } 15 \text { a } 20 \text { de maio de } 2010 \text {. } \\
\text { Na ocasião, foi feita também uma visita ao } \\
\text { Museu da Língua Portuguesa. }\end{array}$ & $\begin{array}{l}\text { Students of the Translation Program } \\
\text { attended the V Ibero-American Congress of } \\
\text { Translation and Interpretation - CIAT, in } \\
\text { São Paulo, from May 15th through 20th, } \\
\text { 2010. They also visited the Portuguese } \\
\text { Language Musuem. }\end{array}$ \\
\hline 107 & $\begin{array}{l}\text { XI Seminário de Linguística Aplicada e VII } \\
\text { Seminário de Tradução }\end{array}$ & $\begin{array}{l}\text { XI Seminar of Applied Linguistics and VII } \\
\text { Seminar of Translation }\end{array}$ \\
\hline 108 & $\begin{array}{l}\text { Os alunos do Curso de Tradução, em viagem } \\
\text { organizada pela coordenação do curso, } \\
\text { participaram do XI Seminário de Linguística } \\
\text { Aplicada e VII Seminário de Tradução, em } \\
\text { Salvador, Bahia, no período de } 12 \text { a } 15 \text { de } \\
\text { novembro de } 2010 \text {. }\end{array}$ & $\begin{array}{l}\text { Students of the Translation Program } \\
\text { attended the XI Seminar of Applied } \\
\text { Linguistics and VII Seminar of Translation, } \\
\text { in Salvador, Bahia, from November 12th } \\
\text { through 15th, 2010. }\end{array}$ \\
\hline
\end{tabular}

Elaboração: Leonardo Penha Mesquita. 
QUADRO 12 - Página da Babel Traduções: Apresentação

\begin{tabular}{|c|c|c|}
\hline Segmento & $\begin{array}{r}\text { Original } \\
\end{array}$ & Tradução \\
\hline 109 & Babel Traduções - Apresentação & Babel Traduções - Overview \\
\hline 110 & Sobre a Babel Traduções & About Babel Traduções \\
\hline 111 & $\begin{array}{l}\text { As empresas juniores são constituídas pela } \\
\text { união de alunos matriculados em cursos de } \\
\text { graduação em instituições de ensino superior, } \\
\text { organizados em uma associação civil, com o } \\
\text { intuito de realizar projetos e serviços que } \\
\text { contribuam para o desenvolvimento do país, } \\
\text { formando profissionais capacitados e } \\
\text { comprometidos com esse objetivo. }\end{array}$ & $\begin{array}{l}\text { A junior enterprise is a civil association } \\
\text { formed by students enrolled in an } \\
\text { undergraduate program. They carry out } \\
\text { projects and services that contribute to the } \\
\text { development of the country, forming trained } \\
\text { professionals committed to this goal. }\end{array}$ \\
\hline 112 & $\begin{array}{l}\text { A Babel Traduções, empresa júnior do Curso de } \\
\text { Tradução (ILEEL/UFU), foi criada em } 2012 \text { e } \\
\text { teve como ponto de partida o projeto de } \\
\text { pesquisa "Tradutores em formação no âmbito } \\
\text { da UFU", cujo objetivo era mapear, nos } \\
\text { diferentes setores da universidade, a procura } \\
\text { por textos traduzidos. }\end{array}$ & $\begin{array}{l}\text { Babel Traduções, a junior enterprise of the } \\
\text { Translation Program (ILEEL/UFU), was } \\
\text { founded in } 2012 \text { from the research project } \\
\text { "Translators Training at UFU", which } \\
\text { aimed to map the demand for translation } \\
\text { services within the university. }\end{array}$ \\
\hline 113 & $\begin{array}{l}\text { O resultado da pesquisa verificou uma } \\
\text { expressiva demanda por serviços de tradução na } \\
\text { esfera institucional, à qual se somaram as } \\
\text { necessidades da comunidade externa, o fluxo de } \\
\text { relações comerciais da cidade de Uberlândia e o } \\
\text { grande volume de informações que circula no } \\
\text { mundo globalizado. }\end{array}$ & $\begin{array}{l}\text { The research found a significant demand for } \\
\text { translation services in the institutional } \\
\text { setting, to which were added the outside } \\
\text { community's needs, the flow of trade } \\
\text { relations to and from the city of Uberlândia } \\
\text { and the great volume of information that } \\
\text { circulates in our globalized world. }\end{array}$ \\
\hline 114 & $\begin{array}{l}\text { Dessa forma, o propósito maior da Babel } \\
\text { Traduções é o de possibilitar aos discentes do } \\
\text { curso - tradutores em formação - a prática de } \\
\text { conhecimentos adquiridos em sala de aula e a } \\
\text { vivência da realidade do mercado de tradução e } \\
\text { revisão (no qual é preciso lidar com prazos, } \\
\text { controle de qualidade, pesquisa, problemas de } \\
\text { tradução, orçamentos etc.), estabelecendo um } \\
\text { elo entre a sociedade e o meio acadêmico. }\end{array}$ & $\begin{array}{l}\text { The main goal of Babel Traduções is to } \\
\text { allow students of the Translation Program to } \\
\text { practice the knowledge acquired in the } \\
\text { classroom and experience the job market } \\
\text { reality (in which one has to deal with } \\
\text { deadlines, quality assurance, research, } \\
\text { translation problems, budgets, etc.), } \\
\text { establishing a link between society and the } \\
\text { academic environment. }\end{array}$ \\
\hline 115 & $\begin{array}{l}\text { A Babel Traduções oferece serviços de tradução } \\
\text { e revisão em diferentes áreas (tradução de } \\
\text { documentos, de conteúdo para sites, de textos } \\
\text { midiáticos e textos acadêmicos, legendagem de } \\
\text { filmes etc.), sempre buscando desenvolver um } \\
\text { trabalho de qualidade junto aos clientes. }\end{array}$ & $\begin{array}{l}\text { Babel Traduções offers translation and } \\
\text { proofreading services in different areas } \\
\text { (documents, sites, media and academic } \\
\text { texts, movies, etc.), always seeking to } \\
\text { provide the client with quality work. }\end{array}$ \\
\hline 116 & $\begin{array}{l}\text { Ao mesmo tempo em que agrega } \\
\text { conhecimentos e práticas à formação dos alunos } \\
\text { participantes, a empresa vem complementar a } \\
\text { missão da Universidade, que é a de desenvolver } \\
\text { idéias e gerar benefícios para o meio no qual } \\
\text { está inserida. }\end{array}$ & $\begin{array}{l}\text { While that adds knowledge and practical } \\
\text { training to its members, the enterprise } \\
\text { complements the university's mission, } \\
\text { which is to develop ideas and generate } \\
\text { benefits for the environment in which it } \\
\text { operates. }\end{array}$ \\
\hline
\end{tabular}

Elaboração: Leonardo Penha Mesquita.

Iniciam-se, neste momento, os comentários da tradução do site. $\mathrm{O}$ primeiro aspecto a ser comentado são as omissões, que representaram nove (7,8\%) dos 116 segmentos processados. Não se trata aqui da omissão considerada um procedimento de tradução, conforme Barbosa (1990), segundo a qual a omissão ocorre por questões gramaticais, intrínsecas ao funcionamento da língua, exigindo, por assim dizer, que haja omissões em favor da acomodação 
das estruturas do original à morfossintaxe da língua de chegada. Trata-se, aqui, na verdade, de omissões de informação. Algumas omissões foram instruídas pela "cliente" enquanto outras, não. As omissões instruídas pela "cliente" referem-se aos segmentos 1, 2, 7, 8 (QUADRO 2) e 61 (QUADRO 5). Aquelas sem instrução da “cliente”, ou seja, a cargo dos autores/tradutores, foram as omissões referentes aos segmentos 58, 62, 67, 70 (QUADRO 5).

Comenta-se, a seguir, a natureza dessas omissões e apresenta-se sua justificativa. Iniciam-se pelos comentários às omissões instruídas pela “cliente".

Os segmentos 1 e 2 contêm informações sobre a avaliação do curso. Como o objetivo do site não é comercial (atrair alunos, por exemplo), a omissão foi feita. A informação de que o curso tenha sido avaliado com nota máxima pelas autoridades competentes não tornaria o texto, na visão dos autores, propagandístico ou comercial. No entanto, concordou-se, no momento do desenvolvimento deste trabalho, com a omissão, por duas razões: (i) em primeiro lugar, uma tradução está condicionada à avaliação do "cliente" e ao que o "cliente" pede que seja feito, ou seja, há uma relação de "obediência" entre "cliente" e tradutor (cf. PYM, 1997; STUPIELLO, 2012); e (ii) seria muito difícil mencionar o MEC sem explicar ao público-alvo (público internacional, sem ser de um local específico) o que significa; e, assim, correr-se-ia o risco de que buscassem uma correspondência, em suas respectivas culturas, de algo que, de fato, poderia não corresponder ao Ministério da Educação no Brasil.

A omissão das informações nos segmentos 7 e 8 devem-se, ao que parece, a questões de atualização e relevância. Já há certo tempo alunos do Curso de Tradução não participam de programas de mobilidade internacional, diferentemente do que ocorria no início do curso. Além disso, como o programa é geralmente destinado a brasileiros, não é muito relevante informar a sua existência a um público internacional sem que, para isso, não sejam feitas adições de informações não presentes no site original.

A omissão das informações contidas no segmento 61 ocorreu devido à sua especificidade, ou seja, são questões internas do funcionamento do curso e dizem respeito à distribuição de vagas. Além disso, sabe-se que o Paaes é uma forma de ingresso que não existe mais na Universidade Federal de Uberlândia, uma vez que foi extinto com a Resolução $n^{\circ}$ 25/2012 do Conselho Universitário (UFU, 2012).

Procede-se agora às omissões a cargo dos autores deste artigo. Conforme já mencionado, elas se referem aos segmentos 58, 62, 67 e 70. A omissão do segmento 58 ocorreu para evitar a repetição de informações que já aparecem em outros lugares do site. As informações do segmento 62 foram realocadas no segmento 60; assim sendo, trata-se de uma 
omissão apenas quando se consideram o segmento 62 e sua posição no site, mas não uma omissão das informações propriamente ditas. A omissão das informações contidas no segmento 67 alinha-se à omissão feita das informações contidas no segmento 61 (instruída pela "cliente”), já que ocorre por se tratar de questões internas específicas do funcionamento do curso (formas de ingresso) e de pouco interesse de um público internacional; além disso, buscou-se evitar a informação genérica já fornecida no segmento 64 e considerou-se que o objetivo da internacionalização seria mais divulgar o curso do que atrair estudantes internacionais. Por fim, a omissão das informações contidas em 70 alinha-se àquela das informações contidas no segmento 58, com a finalidade de evitar a repetição de informações.

Em suma, considerando as omissões instruídas pela "cliente" e as feitas a cargo dos tradutores/autores, podem-se listar os seguintes tipos: (i) omissões ocorridas por questões de objetivo do site; ii) omissões ocorridas por irrelevância de informação para o público-alvo projetado para o site internacionalizado; (iii) omissões ocorridas pelo alto grau de especificidade (funcionamento interno do curso); e (iv) omissões ocorridas para evitar repetições.

O segundo ponto a se comentar sobre a tradução realizada é o significado da palavra training. Seu significado, em inglês, é mais amplo. Num primeiro momento, e principalmente devido à semelhança, a palavra poderia ser traduzida como treinamento. De fato, tem esse significado, mas pode também ser formação (inclusive no âmbito escolar ou universitário). Assim, é possível ver, nos segmentos 21, 22 e 42 training com os seguintes significados, respectivamente: formação, formação profissional e treinamento. Foram realizadas diversas pesquisas em dicionários eletrônicos, e a opção que mais diretamente se adequava a formação (significando, no presente caso, curso) era training. Encontra-se, em alguns materiais, a palavra course, que, na verdade, corresponde à disciplina (matéria lecionada durante um curso) em português.

Um problema semelhante ao do vocábulo training ocorreu com a tradução de dois outros termos: iniciação científica e curso de Letras. Algumas fontes consultadas indicam scientific initiation para iniciação científica. Optou-se, contudo, no segmento 6, por undegraduate research. Sabe-se que se trata de uma iniciação, pois é o primeiro momento, na universidade, em que é possível realizar pesquisas. O termo initiation, além de cognato, não pareceu uma opção segura. Além disso, os programas e o modo de funcionamento dos cursos em universidades de língua inglesa e outras universidades (já que o site traduzido se destina a um público-alvo mais amplo, que lê em inglês, mas não necessariamente que tenha o inglês como 
língua materna) são bastante diferentes. Enquanto o termo undergraduate research é mais abrangente e informa claramente que se trata de uma pesquisa realizada por estudantes ainda num curso de graduação, scientific initiation poderia significar - e não se pode enumerar aqui a variedade de significados - algo distante do que aquilo dito de fato no original.

Esse foi também o caso da tradução de Curso de Letras, no segmento 93. Em algumas fontes consultadas, a opção mais frequente foi Letters Course. Entretanto, não se considerou essa alternativa a opção mais adequada e traduziu-se Curso de Letras por Language and Literature Program. Adiciona-se, nesse aspecto, a questão, já informada, de que course não significa curso, mas sim disciplina no âmbito da linguagem acadêmica.

Caso semelhante ocorre no segmento 87, com a tradução de professora por professor. O verbete do Oxford Advanced Learner's Dictionary, nas acepções 1 e 2, deixa claro: (i) (BrE) "a university teacher of the highest rank" (i.e., professor universitário de mais alto nível); e (ii) (NAmE) "teacher at a university or college" (i.e., professor em uma universidade ou instituição de ensino superior). Assim, não teríamos outra opção para a tradução de professora, tratando-se de uma professora universitária, diferente de teacher.

Embora consciente da diferença de formação e de exigências para se tornar professor universitário nas universidades estadunidenses e inglesas (onde, muitas vezes, se trata do último nível hierárquico e/ou é necessário a livre-docência, um tipo de exigência ou programa inexistente na maioria das universidades federais brasileiras), optou-se por essa tradução, já que, ao que parece, é a que cumpre mais objetivamente a sua função (comunicativa), considerando-se, naturalmente, o público-alvo. Nesse último caso, trata-se mais de uma questão cultural (formação do docente, exigências para ingressar no ensino universitário etc.).

O cunho cultural propiciou uma omissão (não de um segmento completo, como as omissões tratadas anteriormente, mas de uma única informação contida no segmento 20). Tratase do termo REUNI (programa de Reestruturação e Expansão das Universidades Federais), um programa de expansão universitária que permitiu a criação de vários cursos e a contratação de vários docentes, mas que não existe mais. Mesmo que ainda existisse, a informação seria omitida, o que coincide com o procedimento de omissão em relação ao MEC e que alinhado ao objetivo principal do site: divulgação do Curso de Tradução. Assim também, no segmento 60, a sigla ENEM (Exame Nacional do Ensino Médio) é traduzida e explicitada, ou seja, inclui-se brevemente a informação do que significa, enquanto o termo vestibular (um sistema de ingresso coexistente, mas que nunca foi utilizado como forma de ingresso ao Curso de Tradução e que 
difere da maioria dos exames de ingresso em outras universidades mundo afora) foi também omitido.

Resumidamente, pode-se dizer, a respeito da tradução, que todas as opções foram adotadas considerando-se o público-alvo e o objetivo primordial do texto. Dessa forma, houve omissões de informações pouco relevantes para a divulgação do curso, ou seja, informações com marcas culturais muito fortes (como REUNI, vestibular) ou tratando de assuntos muito específicos (formas de funcionamento interno do curso).

Outros problemas percebidos foram quanto à tradução de alguns termos da linguagem acadêmica, como Curso de Letras, Iniciação Científica, que, muitas vezes, se traduzidos literalmente (como algumas opções encontradas em alguns sites e dicionários eletrônicos), não transmitiriam a ideia desejada.

Além disso, a concisão da tradução, perceptível, por exemplo, nos segmentos 4 e 98, deve-se, naturalmente, à forma de estrutura da língua inglesa, ou seja, a língua inglesa tende a ser mais concisa tanto em sua estrutura quanto em seu estilo (RAZO; REGAN; SAENZ, 2011).

Esses foram os fatores internos que mais chamaram a atenção dos autores durante o processo. A título de ilustração, a Figura 4 mostra como ficou uma página internacionalizada do site em tela.

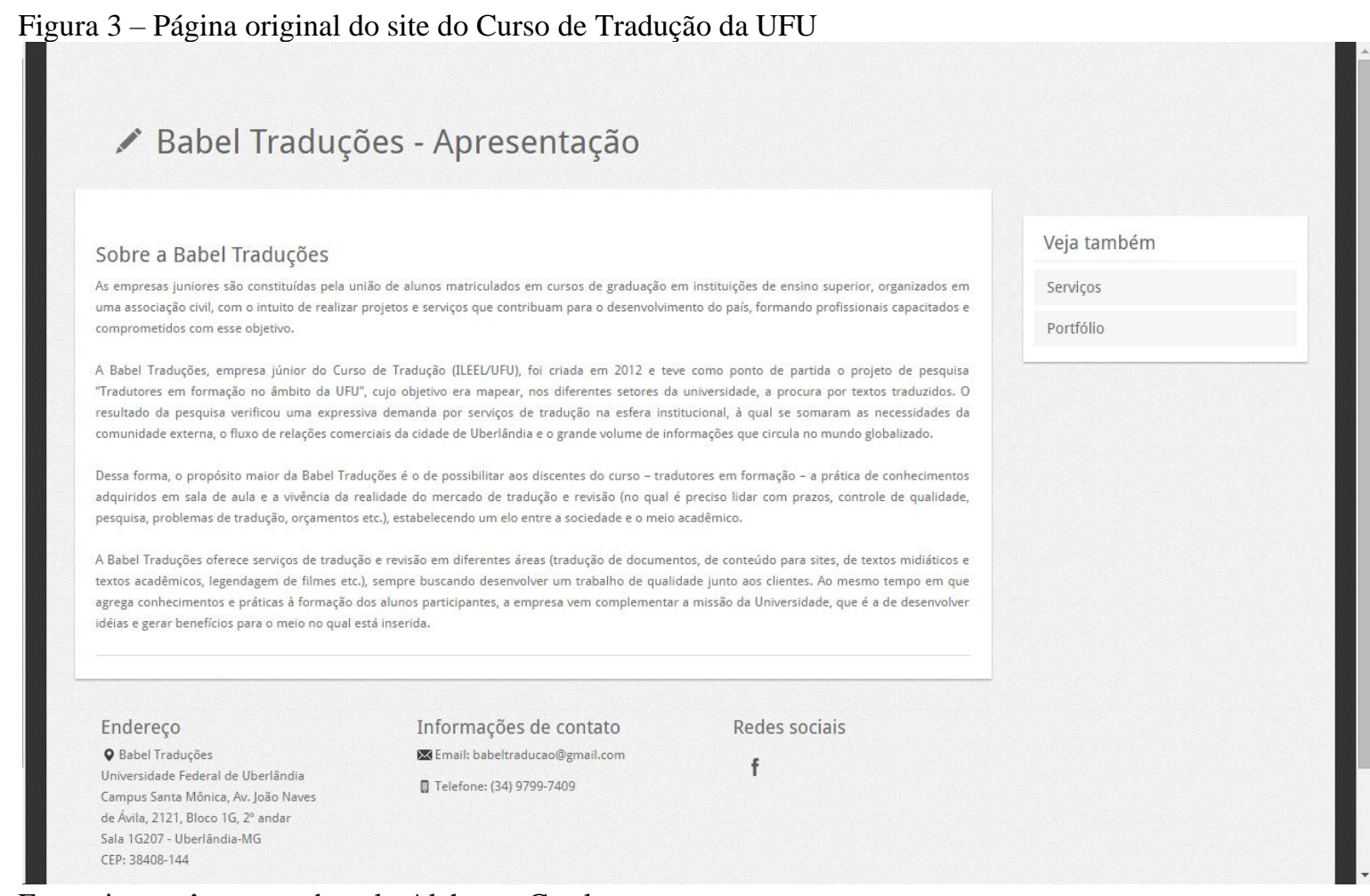

Fonte: instantâneo gerado pelo Alchemy Catalyst. 


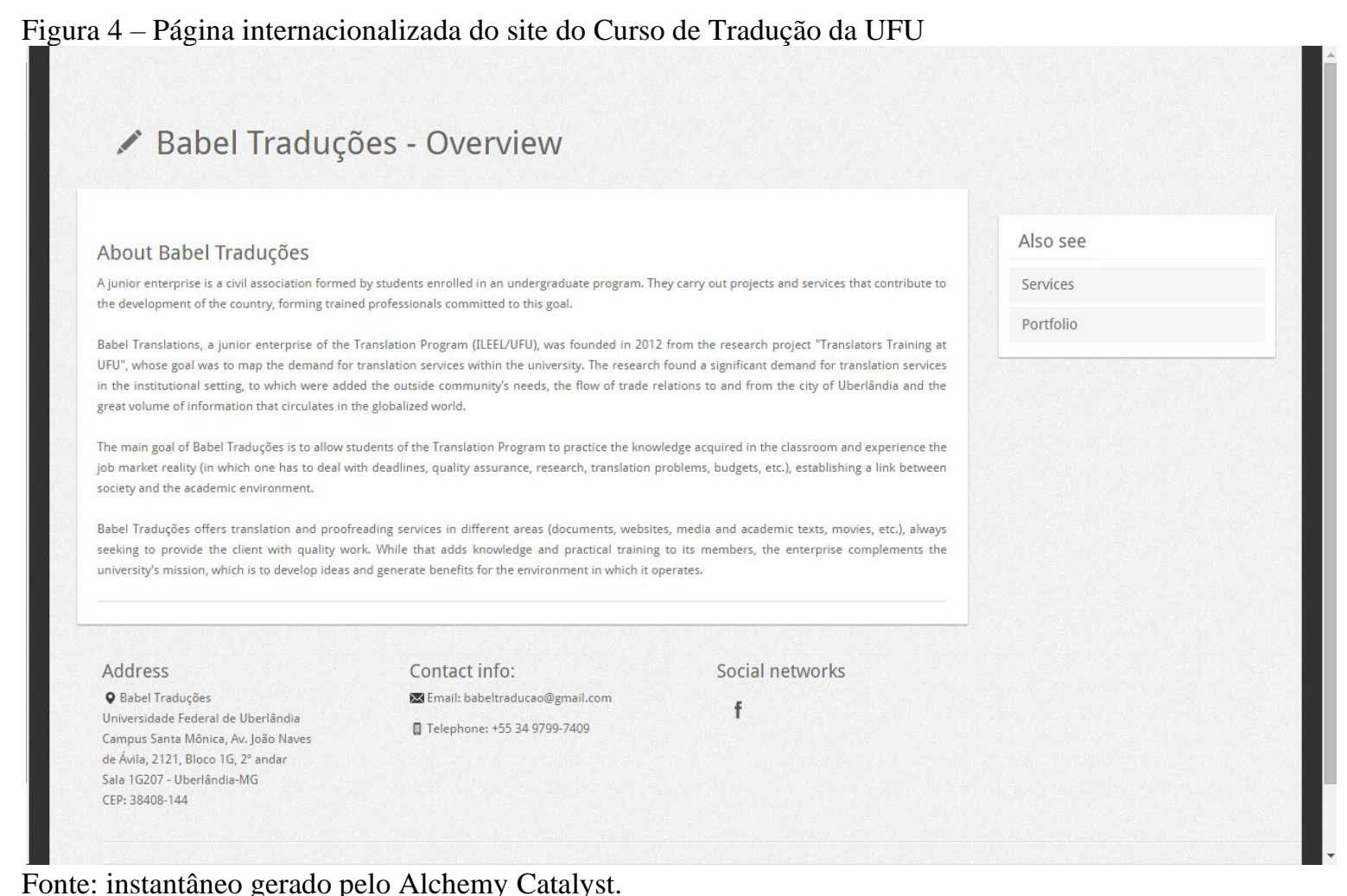

Fonte: instantâneo gerado pelo Alchemy Catalyst.

Como se pode observar, o resultado da tradução usando o Alchemy Catalyst é uma

página bastante similar, em termos de leiaute, à página original. $\mathrm{O}$ que de fato muda é o conteúdo linguístico, podendo-se observar inclusive diminuição de linhas.

\section{CONSIDERAÇÕES FINAIS}

Conforme enunciado na Introdução, a partir da observação de escassez de pesquisas sobre a internacionalização de sites institucionais (FERNÁNDEZ-COSTALES, 2012, 2010), realizou-se um trabalho de tradução de um site universitário com o aporte de uma ferramenta tecnológica. A realização de uma localização com vistas à produção de uma versão internacional do site (JIMÉNEZ-CRESPO, 2010) envolveu um compromisso ético entre tradutores e cliente (PYM, 1997; STUPIELLO, 2012). Com base nas discussões com a “cliente" e na proposta de se realizar uma internacionalização do site voltada para a ampliação da visibilidade do Curso de Tradução no âmbito acadêmico mundial, foram adotadas estratégias que envolveram, dentre outras, a omissão de informações.

Espera-se que o presente artigo desperte reflexões sobre a localização ou internacionalização de sites. Como se pôde observar, esse tipo de atividade exige do tradutor tanto um diálogo franco com o cliente quanto um entendimento claro do público-alvo. Assim, evidencia-se que não se trata de uma mera transposição de conteúdo, mas de tomadas de decisão 
sobre o que será omitido, modificado, explicitado ou adicionado à luz do encargo tradutório e do público-alvo em prospecção. Para além disso, também se logra que o cliente compreenda as decisões tomadas em vez de se surpreender com um site que pode ser "maior" ou "menor" que o original, ou no mínimo "diferente" do que se imaginava que se obteria como resultado. Por fim, destaca-se que a colaboração entre dois tradutores foi relevante principalmente por propiciar a complementação entre indivíduos com diferentes expertises, especialmente numa atividade de tradução inversa, por vezes rechaçadas, mas bastante comum em alguns cenários (DA SILVA, 2019).

\section{REFERÊNCIAS}

ALVES, Fabio. Tradução, cognição e contextualização: triangulando a interface processoproduto no desempenho de tradutores novatos. D.E.L.T.A., São Paulo, v. 39, p. 71-108, 2003. https://doi.org/10.1590/S0102-44502003000300006

ANASTASIOU, Dimitra; SCHÄLER, Reinhard. Translating vital information: localisation, internationalisation, and globalisation. Synthèses, v. 3, p. 13-27, 2010.

70 BARBOSA, Heloísa Gonç

BOWKER, Lynne. Computer-aided translation technology. Ottawa: Ottawa University Press, 2002.

DA SILVA, Igor Antônio Lourenço. An interactional expertise-based approach to specialized inverse translation. Tradução em Revista (online), v. 2019, p. 86-98, 2019. https://doi.org/10.17771/PUCRio.TradRev.40528

DA SILVA, I.A.L; SILVEIRA, F. A. A expertise por interação como condicionante da competência do tradutor de textos técnicos e científicos. Domínios de Lingu@Gem, v. 11, n. 5, p. 1746-1763, 2017. https://doi.org/10.14393/DL32-v11n5a2017-19

FERNÁNDEZ COSTALES, Alberto. Traducción, localización e internacionalización: el caso de las páginas web universitarias. 2010. 552 f. Tese (Doutorado em Tradução) Departamento de Filología Anglogermánica y francesa, Universidad de Oviedo, Oviedo, 2010.

FERNÁNDEZ COSTALES, Alberto. The internationalization of institutional websites: the case of universities in the European Union. In: PYM, Anthony; ORREGO-CARMONA, David (Ed.). Translation research projects. Tarragona: Intercultural Studies Group, 2012. p. 51-60.

GIL, José Ramón Biau; PYM, Anthony. Technology and translation (a pedagogical overview). In: PYM, Anthony; Perekrestenko, Alexander; STARINK, Bram (Ed.). Intercultural Studies Group Universitat Rovira I Virgili, 2010. p. 5-19.

HARTLEY, Tony. Technology and translation. In: MUNDAY, Jeremy (Ed.). The Routledge companion to translation studies. Londres: Routledge, 2009. p. 106-127 
JIMÉNEZ-CRESPO, Miguel. Web internationalization strategies and translation quality: researching the case of "International" Spanish. Localization Focus: The International Journal of Localisation, v. 9, n. 1, p. 13-25, 2010. https://doi.org/10.4324/9780203520208

JIMÉNEZ-CRESPO, Miguel A. Translation and web localization. Londres: Routledge, 2013. LISA, Localization Industry Standards Association. The localization industry primer. 2. ed. Féchy: SMP Marketing and the LISA, 2003.

OXFORD Advanced Learner's Dictionary. Oxford: Oxford University Press, 2005.

PYM, Anthony. Pour une éthique du traducteur. Arras: Artois Presses Université, 1997 apud STUPIELLO, Érika Nogueira de Andrade. Tecnologias de tradução: implicações éticas para a prática tradutória. TradTerm, São Paulo, v. 19, p. 71-91, nov. 2012. https://doi.org/10.11606/issn.2317-9511.tradterm.2012.47346

PYM, Anthony. Website localisation. In: MALMKJAER, Kirsten; WINDLE, Kevin (Ed.). The Oxford Companion to Translation Studies. Oxford: Oxford University Press, 2011. p. 410424.

RAZO, Patricia; REGAN, Elizabeth; SAENZ, Elizabeth. Portuguese manual: language and culture. Trabalho de Conclusão (Graduação) - Texas State University, 2011. Disponível em: http://languagemanuals.weebly.com/uploads/4/8/5/3/4853169/portuguese.pdf. Acesso em: 2 mar. 2020.

SANDRINI, Peter. Website localization and translation. In: MUTRA CONFERENCE, Saarbrücken, 2-6 maio 2005. Proceedings... Saarbrücken: MuTra, 2005. p. 131-138.

SANDRINI, Peter. Localization and translation. MuTra Journal, v. 2, p. 167-191, 2008.

SCHÄLER, Reinhard. Reverse localisation. Localisation Focus: The International Journal of Localisation, v. 6, n. 1, p. 39-48, 2007.

SINGH, Nitish; PEREIRA, Arun. The culturally customized web site: customizing web sites for the global marketplace. Burlington: Elsevier Butterworth, 2005. https://doi.org/10.4324/9780080481333

SNELL-HORNY, Mary. Communicating in the global village: on language, translation and cultural identity. In: SCHÄFFNER, Christina (Ed.). Translation in the global village. Clevedon: Multilingual Matters, 2000. p. 11-28 apud FERNÁNDEZ-COSTALES, Alberto. Traducción, localización e internacionalización: el caso de las páginas web universitarias. 2010. 552 f. Tese (Doutorado em Tradução) - Departamento de Filología Anglogermánica y francesa, Universidad de Oviedo, Oviedo, 2010.

STUPIELLO, Érika Nogueira de Andrade. Tecnologias de tradução: implicações éticas para a prática tradutória. TradTerm, São Paulo, v. 19, p. 71-91, nov. 2012. https://doi.org/10.11606/issn.2317-9511.tradterm.2012.47346 
UFU - UNIVERSIDADE FEDERAL DE UBERLÂNDIA. Conselho Universitário. Resolução $\mathrm{n}^{\circ} 25$, de 20 de novembro de 2012. Dispõe sobre a aplicação da Lei ${ }^{\circ} 12.711$, de 29/8/2012, e demais condições estabelecidas pelo Decreto $n^{\circ} 7.824$ e pela Portaria Normativa do Ministério da Educação $n^{\circ}$ 18/2012, na Universidade Federal de Uberlândia, e dá outras providências. Disponível em: http://www.reitoria.ufu.br/Resolucoes/resolucaoCONSUN-2012-25.pdf. Acesso em: 2 mar. 2020.

YUNKER, John. Building a global web site. Multilingual Computing: The Global Web Guide, v. 55, n. 14, p. 4-9, 2003 apud SANDRINI, Peter. Localization and translation. MuTra Journal, v. 2, p. 167-191, 2008.

\section{Páginas Consultadas}

Stanford, na Califórnia, EUA

http://online.stanford.edu/. Acesso em: 2 mar. 2020.

MIT, em Boston, EUA

http://ocw.mit.edu/index.htm. Acesso: 2 mar. 2020.

Harvard, em Boston, nos EUA

http://www.extension.harvard.edu/open-learning-initiative. Acesso em: 2 mar. 2020.

72 Yale, em Connecticut, nos EUA

http://oyc.yale.edu/. Acesso em: 2 mar. 2020.

Berkeley, na Califórnia, EUA

http://webcast.berkeley.edu/series.html\#c,s,Spring_2013. Acesso em: 2 mar. 2020.

Top 10 U.S. Translation Schools

http://www.altalang.com/beyond-words/2009/09/23/top-10-us-translation-schools/. Acesso

em: 2 mar. 2020.

Gallaudet University

http://interpretation.gallaudet.edu/Interpretation/MA_Program.html. Acesso em: 2 mar. 2020.

Kent State University

http://appling.kent.edu/. Acesso em: 2 mar. 2020.

Monterey Institute

http://www.miis.edu/bethesolution/translation. Acesso em: 2 mar. 2020.

University of Texas, Dallas

http://translation.utdallas.edu/. Acesso em: 2 mar. 2020.

Universitat Autònoma de Barcelona

http://www.uab.cat/web/studying/ehea-degrees/general-information/translation-andinterpreting-1216708259085.html?param1=1228291018508 Acesso em: 2 mar. 2020. 
Harvard University

http://www.harvard.edu/. Acesso em: 2 mar. 2020.

Yale University

http://www.yale.edu/. Acesso em: 2 mar. 2020.

Boston University

http://www.bu.edu/. Acesso em: 2 mar. 2020.

\section{Dicionários Consultados}

Online Collocation Dictionary

http://oxforddictionary.so8848.com/o\#.VaQfsPlVikq. Acesso em: 2 mar. 2020.

Oxford Dictionaries

http://www.oxforddictionaries.com/. Acesso em: 2 mar. 2020.

Synonym

http://www.synonym.com/. Acesso em: 2 mar. 2020.

Urban Dictionary

http://www.urbandictionary.com/. Acesso em: 2 mar. 2020.

Linguee

http://www.linguee.com.br. Acesso em: 2 mar. 2020.

1 "[...] all of the business decisions and activities required to make an organization truly international in scope and outlook. Globalization is the transformation of business and processes to support customers around the world, in whatever language, country, or culture they require." (LISA, 2003, p. 1)

2 "[...] abstracting the functionality of a product away from any particular language so that language support can be added back in simply, without worry that language-specific features will pose a problem when the product is localized." (LISA, 2003, p. 14)

3 “[...] process of modifying a product for a specific locale." (YUNKER, 2002, p. 17 apud SANDRINI, 2008, p. 3)

4 "[...] a set of parameters used to identify the user's language, country and other preferences. It is roughly the combination of a language and a geographical region with all the cultural implications involved. For example, a country, a region, or a city. A locale is not a culture since a culture is more comprehensive, much more rooted and much less volatile than a locale." (SANDRINI, 2008, p. 168)

5 “[...] all non-material components of an electronic system." (SANDRINI, 2008, p. 169)

${ }^{6}$ Com o desenvolvimento tecnológico, sobretudo com o surgimento da "nuvem" e formas de tradução em massa ("crowdsourcing"), é possível que essa diferenciação entre software e website, em termos de dinamismo e funcionalidade, torne-se cada vez mais tênue ou mesmo inócua.

${ }^{7}$ Os dicionários consultados estão explicitados ao final das Referências.

${ }^{8}$ Os sites de universidades estrangeiras consultados estão explicitados ao final das Referências.

\section{NOTA DOS AUTORES}

Leonardo Penha MESQUITA - Bacharel em Tradução (2015) pela Universidade Federal de Uberlândia. Pesquisador autônomo. Ribeirão Preto, São Paulo, Brasil.

ORCID: https://orcid.org/0000-0003-0870-5569

Currículo acadêmico: http://lattes.cnpq.br/1012831996041287

E-mail: lpmesquita@gmail.com 
Igor A. Lourenço DA SILVA - Professor adjunto na Universidade Federal de Uberlândia. Membro permanente dos Programas de Pós-graduação em Estudos Linguísticos da Universidade Federal de Minas Gerais (POSLIN) e da Universidade Federal de Uberlândia (PPGEL). Doutor (2012) e Mestre (2007) em Estudos Linguísticos pela Universidade Federal de Minas Gerais. Licenciado (2004) e Bacharel (2003) em Letras - Inglês pela mesma instituição. Universidade Federal de Uberlândia, Instituto de Letras e Linguística, Bacharelado em Tradução. Uberlândia, Minas Gerais, Brasil.

ORCID: https://orcid.org/0000-0003-0738-3262

Currículo acadêmico: http://lattes.cnpq.br/6440150670404908

E-mail: ials@ufu.br 